\title{
Microstructure and mechanical properties of nickel processed by accumulative roll bonding
}

Zhang, Yubin; Mishin, Oleg; Kamikawa, N.; Godfrey, A.; Liu, W.; Liu, Q.

Published in:

Materials Science and Engineering: A - Structural Materials: Properties, Microstructure and Processing

Link to article, DOI:

10.1016/j.msea.2013.04.002

Publication date:

2013

Link back to DTU Orbit

Citation (APA):

Zhang, Y., Mishin, O., Kamikawa, N., Godfrey, A., Liu, W., \& Liu, Q. (2013). Microstructure and mechanical properties of nickel processed by accumulative roll bonding. Materials Science and Engineering: $A$ - Structural Materials: Properties, Microstructure and Processing, 576, 160-166. https://doi.org/10.1016/j.msea.2013.04.002

\section{General rights}

Copyright and moral rights for the publications made accessible in the public portal are retained by the authors and/or other copyright owners and it is a condition of accessing publications that users recognise and abide by the legal requirements associated with these rights.

- Users may download and print one copy of any publication from the public portal for the purpose of private study or research.

- You may not further distribute the material or use it for any profit-making activity or commercial gain

- You may freely distribute the URL identifying the publication in the public portal 
Science \& Engineering A

Elsevier Editorial System(tm) for Materials

Manuscript Draft

Manuscript Number: MSEA-D-12-03899R1

Title: Microstructure and mechanical properties of nickel processed by accumulative roll bonding

Article Type: Research Paper

Keywords: EBSD; electron microscopy; mechanical characterization; nickel; bulk deformation; grain refinement

Corresponding Author: Dr. Yubin Zhang, Ph.D

Corresponding Author's Institution: Technical University of Denmark

First Author: Yubin Zhang, Ph.D

Order of Authors: Yubin Zhang, Ph.D; O.V. Mishin, Ph.D; N. Kamikawa, Ph.D; A. Godfrey, Ph.D; W. Liu, Ph.D; Q. Liu, Ph.D

Abstract: A detailed investigation of the microstructure and mechanical properties has been conducted in pure nickel deformed to high strains using accumulative roll bonding (ARB). Samples have been investigated after different numbers of $A R B$ cycles and the results have been compared with data for nickel processed by other deformation techniques, with particular focus on conventional rolling. It is found that the structural evolution in ARB-processed nickel is rapid at low strains followed by a slower evolution as the strain approaches ultrahigh levels. Comparing samples processed by $A R B$ and conventional rolling to an identical nominal strain, the microstructure after ARB is more refined and contains a greater fraction of high angle boundaries. This enhanced refinement is attributed to the geometric accumulation of shear-strain influenced volumes as a result of the ARB process and large-draught rolling conditions. Based on the observations, it is suggested that the key strengthening mechanisms in deformed nickel are grain boundary and dislocation boundary strengthening, and that the strength-microstructure relationship can be expressed by a single parameter equation, $\sigma-\sigma 0=$ $\mathrm{k} 2$ dav-0.5, where $\mathrm{k} 2$ is a constant and dav is the average boundary spacing in the deformed microstructure. 


\title{
Microstructure and mechanical properties of nickel processed by accumulative roll bonding
}

\author{
Y.B. Zhang ${ }^{\text {a, c, * }}$, O.V. Mishin ${ }^{\text {a }}$, N. Kamikawa ${ }^{b}$, A. Godfrey ${ }^{c}$, W. Liu ${ }^{c}$, Q. Liu ${ }^{d}$ \\ ${ }^{a}$ Danish-Chinese Center for Nanometals, Department of Wind Energy, Technical University of Denmark, \\ Ris $\varnothing$ campus, 4000 Roskilde, Denmark \\ ${ }^{\mathrm{b}}$ Institute for Materials Research, Tohoku University, 2-1-1 Katahira, Aoba-ku, Sendai 980-8577, Japan \\ ${ }^{\mathrm{c}}$ Laboratory of Advanced Materials, Department of Materials Science and Engineering, Tsinghua \\ University, Beijing 100084, P.R. China \\ ${ }^{\mathrm{d}}$ School of Materials Science and Engineering, Chongqing University, Chongqing 400030, P.R. China \\ *Corresponding author. Tel.: 0045 46775876; Fax.: 0045 46775758; Email address: yubz@dtu.dk; Postal \\ address: Frederiksborgvej 399, Building 228, Roskilde, 4000, Denmark
}

Abstract: A detailed investigation of the microstructure and mechanical properties has been conducted in pure nickel deformed to high strains using accumulative roll bonding (ARB). Samples have been investigated after different numbers of ARB cycles and the results have been compared with data for nickel processed by other deformation techniques, with particular focus on conventional rolling. It is found that the structural evolution in ARB-processed nickel is rapid at low strains followed by a slower evolution as the strain approaches ultrahigh levels. Comparing samples processed by $\mathrm{ARB}$ and conventional rolling to an identical nominal strain, the microstructure after $\mathrm{ARB}$ is more refined and contains a greater fraction of high angle boundaries. This enhanced refinement is attributed to the geometric accumulation of shear-strain influenced volumes as a result of the ARB process and large-draught rolling conditions. Based on 
the observations, it is suggested that the key strengthening mechanisms in deformed nickel are grain boundary and dislocation boundary strengthening, and that the strength-microstructure

relationship can be expressed by a single parameter equation, $\sigma-\sigma_{0}=k_{2} d_{\mathrm{av}}{ }^{-0.5}$, where $k_{2}$ is a constant and $d_{\mathrm{av}}$ is the average boundary spacing in the deformed microstructure.

Keywords: EBSD; electron microscopy; mechanical characterization; nickel; bulk deformation; grain refinement

\section{Introduction}

Considerable interest in materials processed using severe plastic deformation (SPD) techniques exists as a result of the possibility to refine the microstructure by heavy deformation to a submicron- and nanostructured range, which results in very high levels of mechanical strength [1]. One of the most attractive and easily implementable SPD processes is accumulative roll bonding (ARB), which comprises repetitive cycles of rolling (typically 50\% reduction), followed by cutting of the rolled material in half, and stacking the halves to be rolled again in a subsequent cycle [2]. As the thickness of the rolled sample is kept constant at the end of each ARB cycle, the process can be continued to very high strains. For example, a von Mises strain of 6.4 is reached by eight ARB cycles of $50 \%$ reduction, after which the sample is still only two times thinner than the initial material. Although it is also possible to reach such a high strain by conventional rolling (CR) [3], the initial material should be at least $\sim 250$ times thicker than the final required sample thickness, and a large number of rolling passes will be necessary to achieve such strains. 
For several materials deformed by ARB it has been shown that submicron structures with large fractions of high angle boundaries (HABs) can be obtained already after 6 cycles. Although there have been a large number of studies of ARB-processed aluminum, copper, steels and titanium [4-15], there are very few publications describing the evolution of the microstructure during $\mathrm{ARB}$ of nickel. For example, the microstructure and texture of ARB-processed Ni were characterized after 8 cycles [16,17]. Large fractions of HABs (60-64\%) were revealed by the EBSD technique in this material, however, the changes taking place during ARB at low and intermediate strains have not been evaluated in Refs.[16,17]. One study [18] did consider the changes in the fraction of HABs and the average misorientation angle with increasing number of ARB cycles. However, the evolution of the key parameter of boundary spacing has not been analyzed there, and the evolution of tensile properties of nickel after different numbers of ARB cycles has not been reported.

One objective of the present work is, therefore, a study of the evolution of microstructural parameters in $\mathrm{Ni}$ deformed by the $\mathrm{ARB}$ process to high strains of up to $\varepsilon=6.4$. It is of interest also to compare the microstructural evolution during ARB with that during conventional coldrolling, which is done by considering samples deformed to identical von Mises strains. To enable a comprehensive description of the microstructure, both electron backscatter diffraction (EBSD) and transmission electron microscopy (TEM) techniques are utilized to determine a number of structural parameters, allowing also a comparison between results obtained using these two characterization techniques. Another key objective is to examine the relationship between mechanical behavior and microstructure over a wide strain range. Results obtained for the ARBprocessed material through a series of tensile tests and hardness measurements are compared with 
those in nickel deformed using other processing techniques, and the relationship between mechanical properties and microstructure is analyzed by considering the relative contributions from both dislocation boundary strengthening and grain boundary (GB) strengthening.

\section{Experimental}

The material used in this study was 99.97\% pure nickel (see Table 1) cold-rolled to $2 \mathrm{~mm}$ and annealed to produce a fully recrystallized microstructure with a nearly random texture (Fig. 1). The average grain size in this recrystallized sample was measured to be $\sim 20 \mu \mathrm{m}$ including twins and $\sim 40 \mu \mathrm{m}$ excluding twin boundaries. Several $30 \mathrm{~mm}$ wide and $300 \mathrm{~mm}$ long strips of this annealed material were used to produce samples after different numbers of ARB cycles.

A $2 \mathrm{~mm}$ thick strip was cold-rolled 50\% using well-lubricated rolls with a diameter of $310 \mathrm{~mm}$. The obtained $1 \mathrm{~mm}$ thick strip was then cut in half. After degreasing and wire-brushing, the halves were stacked and rolled 50\% again, creating a bonding between the two halves. This roll-bonding operation was conducted repeatedly. The largest number of ARB cycles used for one initial strip was 8 , which corresponds to a total von Mises strain of $\varepsilon_{\mathrm{vM}}=6.4$. One sample (CR sample) of the same initial material was also deformed by conventional rolling to $\varepsilon_{\mathrm{vM}}=2.4$, for comparison with the ARB sample after 3 cycles. To reduce shear during conventional rolling, the CR sample was deformed applying intermediate draughts under conditions of $0.5 \leq l / h \leq 5$, where $l$ is the length of contact between the rolls and the specimen and $h$ is the mean sample 
thickness [19]. In contrast, the counterpart ARB sample was prepared using large draught rolling conditions $(l / h>5)$.

Samples after 3, 4, 5, 6 and 8 ARB cycles, as well as the CR sample, were investigated using both TEM and EBSD. In addition, EBSD data were obtained on two other samples, conventionally rolled from a different initial material to $\varepsilon_{\mathrm{vM}}=2.7$ and 4.5 , that were previously characterized using TEM [20]. The microstructure of the deformed samples was studied in the longitudinal section containing the normal and rolling directions (ND and RD, respectively). EBSD maps from these samples were collected in a Zeiss Supra 35 field emission gun scanning electron microscope equipped with a Channel 5 system. A fixed step size of $30 \mathrm{~nm}$ was selected for collecting EBSD data used for a quantitative analysis of the microstructure. A larger step size, $50 \mathrm{~nm}$, was used for revealing microstructural heterogeneities. For each ARB sample, a large number of regions were covered at different depths to make sure that average values represent microstructural parameters of the entire sample.

Tensile tests of the ARB-processed samples were conducted at room temperature by pulling the specimens along the RD. Tensile specimens with a gauge length of $10 \mathrm{~mm}$, a width of $5 \mathrm{~mm}$ and a thickness of $1 \mathrm{~mm}$ were used. The tests were carried out at a constant crosshead speed of $0.5 \mathrm{~mm} / \mathrm{min}$, which corresponds to an initial strain rate of $8.3 \times 10^{-4} \mathrm{~s}^{-1}$. Vickers hardness measurements were conducted on the rolling plane with a load of $200 \mathrm{~g}$.

\section{Results}

A mixture of structures inclined at large angles to the rolling plane, and of structures almost parallel to the rolling plane are seen after 3 ARB cycles $\left(\varepsilon_{\mathrm{v} M}=2.4\right)$, see Fig.2a. Such structures have been described in the literature as dense dislocation walls, microbands 
(DDWs / MBs) and lamellar structures, respectively [20,21]. With increasing number of cycles, the microstructure is dominated by lamellae nearly parallel to the rolling plane, with short interconnecting boundaries within the lamellae (Fig.2b,c). Evidence of localized shear was also observed in the inspected samples. Whereas bonding during the ARB process was mostly good, regions of incomplete bonding were also occasionally found, as shown in Figure 3, where incomplete bonding is observed near a coarse oxide particle.

The EBSD maps in Fig.2 indicate that the frequency of HABs increases with increasing number of ARB cycles. The changes in the fraction of HABs $\left(f_{\mathrm{HAB}}\right)$ calculated from the EBSD data, where only misorientations $>1.5^{\circ}$ are considered, are further quantified in Fig.4a. It is seen that $f_{\mathrm{HAB}}$ increases rapidly from 3 to 5 cycles. After 5 cycles the increase in $f_{\mathrm{HAB}}$ becomes less pronounced. In the 8 -cycle sample, $f_{\mathrm{HAB}}$ reaches $\sim 60 \%$. The slower evolution of the microstructure after a large number of cycles is also reflected in the spacing between HABs $\left(d_{\mathrm{HAB}}\right.$ in Fig.4b).

It should be noted that whilst the value of $d_{\mathrm{HAB}}$ is not affected by the limited angular resolution of the EBSD technique, the spacing between low angle boundaries (LABs) cannot be measured accurately by traditional EBSD because boundaries with very low misorientations are not confidently distinguished due to the presence of orientation noise in the EBSD data [22,23]. For this reason the critical misorientation angle for the EBSD data is set in this work at $1.5^{\circ}$. Thus, a certain number of true low angle boundaries are missing in the EBSD maps. Obviously, the fraction of missing LABs can be very significant in samples deformed to comparatively low strains, where very low misorientations are especially frequent. Comparison of the EBSD map and TEM image from the 3-cycle sample (Fig.2a and Fig.5, respectively) shows that, in a tilt position with a low-index zone axis aligned almost parallel to the incident-beam direction, TEM 
reveals many more boundaries per unit area than EBSD mapping of a similar region. Therefore, TEM images were used in this work for measuring the spacing between all boundary types $\left(d_{\text {all }}\right)$.

Figure $4 \mathrm{~b}$ shows that, with increasing strain, $d_{\text {all }}$ along the ND decreases more slowly than the HAB spacing $\left(d_{\mathrm{HAB}}\right)$. The difference in the values of these two parameters thus becomes smaller after a large number of ARB cycles. However, even after 8 cycles $d_{\mathrm{HAB}}$ is considerably greater than $d_{\text {all }}(\sim 210 \mathrm{~nm}$ and $110 \mathrm{~nm}$, respectively).

Example stress-strain curves and the average parameters of strength and ductility are shown in Fig.6 and Fig.7, respectively. It is seen that the strength of the ARB-processed material increases with increasing number of cycles and that this increase is accompanied by a reduction in ductility. The increase in the $0.2 \%$ proof stress is rapid after a small number of ARB cycles and slows down significantly after 5 cycles (see Fig.7). After 8 cycles the $0.2 \%$ proof stress is almost $710 \mathrm{MPa}$. The uniform elongation is, however, quite low, $2 \%$.

\section{Discussion}

\subsection{Microstructural evolution}

Since the deformation in the ARB-process is conducted by rolling, it can be expected that the microstructural evolution of ARB-processed nickel should be similar to that observed after conventional rolling. Indeed, the morphology of the microstructure within the stacked and rolled layers is very similar to that in conventionally rolled nickel. According to Hughes and Hansen [20,21], the evolution of the microstructure with increasing rolling reduction is characterized by a transition from a microstructure dominated by DDWs / MBs to a lamellar type structure. As shown for cold-rolled nickel [20,21], the transition between the two types of microstructure 
occurs gradually within the strain range, $0.8-2.7$. In agreement with these findings, a combination of DDWs / MBs and lamellar structures is still observed in our material after 3 ARB cycles $\left(\varepsilon_{\mathrm{vM}}=2.4\right)$.

Despite these similarities, there are some important differences between the microstructures in conventionally rolled and ARB-processed Ni samples, related mostly to the presence of multiple near-interface volumes throughout the thickness of the ARB samples. To enable direct quantitative comparison between the microstructure of the ARB-processed and conventionally rolled $\mathrm{Ni}$, the data for the $\mathrm{CR}$ sample deformed to a strain of 2.4 (see Experimental) are also considered in this work. Comparing the CR and ARB samples after the same strain (Table 2), it is evident that the spacings between both LABs and HABs are smaller in the ARB-processed sample and that the fraction of HABs is higher than that in the CR sample. The difference in the boundary distribution between the different samples is especially pronounced for misorientations less than $3^{\circ}$ (Fig.8).

To obtain further information on the extent of structural subdivision by HABs, the total length of $\mathrm{HAB}$ traces per unit area, $\mathrm{L}_{\mathrm{A}[\mathrm{HAB}]}$, was determined from the EBSD data as described in Ref. [24]. It is evident that also this parameter is significantly different in the two samples (see Table 2). The fact that ARB produces a more refined microstructure and a higher frequency of closely spaced HABs than conventional rolling is attributed to a greater number of subsurface layers in the body of the ARB sample. These layers experience additional shear deformation, enhanced by the large-draught rolling conditions [25] used during the ARB process. A larger effective strain makes the microstructure more refined and increases the fraction of HABs in the ARB stack [26], which results in its higher hardness compared to the CR sample (see Table 2). 
Our observation of the overall finer boundary spacing in nickel after ARB as compared to conventional rolling is consistent with previous findings made for aluminum [27].

At strains higher than 2.4, the microstructure of ARB-processed $\mathrm{Ni}$ evolves into a predominantly lamellar type, where individual lamellae are frequently delineated by HABs. At strains above $4-5$ the structural evolution continues at a slower rate with no saturation observed in the investigated strain range (see Fig.4). At the highest strain $\left(\varepsilon_{\mathrm{vM}}=6.4\right)$, the boundary spacing is $110 \mathrm{~nm}$ and the fraction of $\mathrm{HABs}$ is $\sim 60 \%$, which are similar to the data reported for ARBprocessed nickel in $[16,17]$. These values are however very different from the saturation values recorded at $\varepsilon_{\mathrm{vM}} \geq 34$ for Ni deformed by high pressure torsion (HPT) [28]. At such large strains the fraction of HABs in HPT-deformed Ni was about $70 \%$ and the boundary spacing saturated at $\sim 50 \mathrm{~nm}$ as measured using TEM [28]. HAB fractions of about $70 \%$ were also reported in $\mathrm{Ni}$ processed by equal channel angular pressing after a strain of $\sim 12[29,30]$, however these values were based on the EBSD data where misorientations less than $2^{\circ}$ were not taken into account.

Compared to other commonly investigated face centered cubic metals, the microstructure of $\mathrm{Ni}$ heavily deformed by ARB is more refined than in aluminum and similarly refined to that in copper. For example, in commercial purity aluminum the boundary spacing along the ND is 230-240 nm after 6 to 8 cycles [12,27], i.e. two times greater than the values recorded for our $\mathrm{Ni}$ samples after the same number of cycles (see Fig.4). It is important to note also that, depending on the purity, recrystallized grains can appear in copper even after a comparatively small number of ARB cycles [12,31].

4.2 Analysis of mechanical behavior 
As expected, the decrease in the boundary spacing with increasing strain results in significant strengthening of the ARB material (Figs 6,7). To rationalize the strengthening mechanism in detail, the relationship between the average boundary spacing $d_{\mathrm{av}}$ measured along random lines in the TEM images and the strength can be analyzed in a quantitative manner using a Hall-Petch plot, as shown in Fig. 9. From this figure it is seen that the strength of the ARB samples follows an apparent Hall-Petch type relationship with respect to $d_{\mathrm{av}}$ over the strain range examined. Moreover, by adding the data from other Ni samples heavily deformed by either conventional rolling [20,32] or high pressure torsion (HPT) [33], it is seen that this relationship holds for a wide range of $d_{\mathrm{av}}$, which suggests that the strengthening mechanism for the ARBprocessed samples and for the samples produced by CR and HPT are similar. Note that the values of $d_{\mathrm{av}}$ in [33] were determined by TEM in the same way as for the present ARB data, while for the rolled samples in [32] the TEM data were reported in the form of the average spacings between geometrically necessary boundaries (GNBs) and incidental boundaries (IDBs), $d_{\mathrm{GNB}}$, and $d_{\mathrm{IDB}}$, respectively. To allow a direct comparison with the average boundary spacings measured along test random lines the data were therefore converted using the exact stereological relationship:

$$
d_{\mathrm{av}}=\pi /\left(2 \mathrm{~L}_{\mathrm{A}[\mathrm{av}]}\right)
$$

where $\mathrm{L}_{\mathrm{A}[\mathrm{av}]}$ is the total boundary length per unit area for both GNBs and IDBs:

$$
\mathrm{L}_{\mathrm{A}[\mathrm{av}]}=\mathrm{L}_{\mathrm{A}[\mathrm{GNB}]}+\mathrm{L}_{\mathrm{A}[\mathrm{IDB}]}=1 / d_{\mathrm{GNB}}+1 / d_{\mathrm{IDB}}
$$

A fitting of the slope in Fig. 9 yields a value for the apparent Hall-Petch coefficient $\left(k_{2}\right)$ [34] of $345 \pm 7 \mathrm{MPa} \mu \mathrm{m}^{0.5}$ and a friction stress $\left(\sigma_{0}\right)$ value of $8 \pm 18 \mathrm{MPa}$. This value of $k_{2}$ is approximately 
two times greater than the value previously reported for annealed nickel [35], where a value of $k_{\mathrm{HP}}=159 \mathrm{MPa} \mu \mathrm{m}^{0.5}$ was found.

To rationalize the difference between the slopes in Hall-Petch plots for heavily deformed and conventional samples, the strength-microstructure relationship have been previously analyzed taking into account contributions of different types of deformation-induced boundaries, i.e. IDBs and GNBs $[20,36]$. In this analysis, the IDBs are assumed to be penetrable to slip and contribute to the strength via forest hardening, while the GNBs are assumed to be effective barriers for slip and therefore their contribution is via grain boundary strengthening [20]. However, in microstructures after very high strains it is not always possible to unambiguously distinguish between GNBs and IDBs. For such materials it may be more appropriate to make a distinction between these two different types of boundaries based on the misorientation angle across them, where it is assumed that boundaries with misorientation below a certain critical angle $\left(\theta_{\mathrm{c}}\right)$ contribute to the strength via dislocation strengthening, whereas boundaries with misorientations higher than $\theta_{\mathrm{c}}$ contribute to the strength via GB strengthening. According to Refs [34,37], the flow stress can, in this case, be described as:

$$
\sigma=\sigma_{0}+M \alpha G b \sqrt{\rho_{0}+\frac{3(1-f) \theta_{a v}}{b d_{a v}}}+k_{H P} \sqrt{\frac{f}{d_{a v}}}
$$

where $k_{\mathrm{HP}}$ is the slope of a Hall-Petch plot for annealed polycrystalline nickel $\left(159 \mathrm{MPa} \mu \mathrm{m}^{0.5}\right.$ [35]), $f$ is the fraction of boundaries with misorientation angles above $\theta_{\mathrm{c}}, M \approx 3$ is the Taylor factor, $\alpha \approx 0.24$ is a constant, $G=79 \mathrm{GPa}$ is the shear modulus, $b=0.249 \mathrm{~nm}$ is the Burgers vector, $\theta_{\mathrm{av}}$ is the average misorientation angle for boundaries with misorientations below $\theta_{\mathrm{c}}, \sigma_{0}$ is 
the friction stress, and $\rho_{0}$ is the dislocation density between boundaries. In our samples $\rho_{0}$ is sufficiently low that its contribution can be neglected. Eq. 3 can therefore be written in the following form $[34,38]$ :

$$
\begin{aligned}
& \sigma-\sigma_{0}=\left\lfloor M \alpha G \sqrt{3 b \theta_{a v}(1-f)}+k_{H P} \sqrt{f}\right\rfloor d_{a v}^{-0.5} \\
& \sigma-\sigma_{0}=k_{2} d_{a v}^{-0.5}
\end{aligned}
$$

To calculate $k_{2}$ from Eqs 4 and 5, it is first necessary to define the critical angle $\theta_{\mathrm{c}}$. For heavily deformed Fe this angle has previously been estimated to be $\sim 5^{\circ}$ [38]. In our work we applied $\theta_{\mathrm{c}}=4$ and $6^{\circ}$ to calculate the values of $k_{2}$ for both $\mathrm{CR}$ and ARB samples investigated using TEM and/or EBSD techniques. At both $\theta_{\mathrm{c}}=4^{\circ}$ and $\theta_{\mathrm{c}}=6^{\circ}$ a very good agreement is obtained between the calculated TEM-based $k_{2}$ values (see Table 3) and the $k_{2}$ value in Fig. 9. Although at $\theta_{\mathrm{c}}=6^{\circ}$ the values of $f$ and $\theta_{\mathrm{av}}$ from the EBSD data differ from the corresponding values in the TEM data sets, the value of $k_{2}$ is still similar to the one in Fig.9. Apparently, the effect of a reduction in $f$, caused by ignoring very low misorientation boundaries in the EBSD data, is counterbalanced by increased $\theta_{\mathrm{av}}$ (see Table 3). It is significant that for the same characterization approach the values of $k_{2}$ for the CR and ARB samples deformed to comparable strains are very similar, which confirms the similarity of the strengthening mechanisms in these two kinds of samples.

Whereas an increase in strength with increasing number of ARB cycles is consistently observed for various materials, the literature data describing the evolution of ductility with ARB processing are less consistent. It is apparent that the ductility is significantly reduced in the deformed microstructure as compared to the initial annealed material. However, the further 
evolution of ductility with increasing strain appears to be different in different ARB materials. For example, in some Al-alloys the tensile elongation remains quite low regardless of the number of ARB cycles, being either almost insensitive to the accumulated strain or showing a clear tendency to decrease as the number of cycles increases [5-8]. However, in other ARB-processed Al samples the ductility represented in terms of the total elongation to failure increases substantially with increasing number of cycles $[6,9]$. The reason for this discrepancy between the different Al-samples may be related to the strain rate dependence effect [9] since strain rates were not identical in the different experiments.

For the Ni samples studied in the present experiment, both the total elongation (see Fig.6) and uniform elongation (Fig.7) are very low over a wide range of ARB cycles, which is similar to the findings for the $1 \mathrm{XXX}$ and $6 \mathrm{XXX}$ series $\mathrm{Al}$-alloys described in [5-8]. Similar to the approaches taken for improving low ductility in the ARB-processed Al-alloy, it may be possible to restore some ductility in ARB-Ni while still maintaining a high level of strength by use of controlled annealing treatments. Previous experiments on SPD nickel indicate however that the processing window to avoid recrystallization is likely to be very narrow [39].

\section{Conclusions}

The microstructure and mechanical properties have been studied in pure Ni deformed by ARB over a wide strain range. Results from the ARB material after a von Mises strain of 2.4 have additionally been compared with those obtained for the same initial material after conventional rolling to the same strain. The following conclusions are drawn from this work. 
1. During ARB the microstructure evolves rapidly at low strains followed by a slower evolution at high strains $\left(\varepsilon_{\mathrm{vM}}>4\right)$. At $\varepsilon_{\mathrm{vM}}=6.4$ the fraction of high angle boundaries is $60 \%$ and the boundary spacing along the normal direction is $110 \mathrm{~nm}$.

2. Comparison of the ARB and conventionally rolled CR samples deformed to $\varepsilon_{\mathrm{vM}}=2.4$ reveals that their microstructures are morphologically similar. However, the ARB microstructure is more refined and contains a greater fraction of high angle boundaries than the CR sample, which is attributed to a large number of layers that experienced shear deformation in the ARB material. The greater refinement in the ARB sample results in a higher value of hardness as compared to the CR sample.

3. The strength of ARB-processed Ni increases with increasing number of cycles, resulting in a $0.2 \%$ proof stress after $8 \mathrm{ARB}$ cycles of $\sim 740 \mathrm{MPa}$. The ductility of this material is however very low $(<2 \%)$ over a large number of cycles.

4. The microstructure and strength of SPD-processed $\mathrm{Ni}$ can be related over a wide range of strain by an apparent Hall-Petch relationship, i.e. a one-parameter equation of the form $\sigma-\sigma_{0}=k_{2} d_{a v}^{-0.5}$, where $d_{a v}$ is the average boundary spacing in the deformed microstructure and $k_{2}$ is a constant. The value of $k_{2}$ can be estimated based on contributions from dislocation boundary and grain boundary strengthening.

\section{Acknowledgements}

The authors gratefully acknowledge support from the Danish National Research Foundation and the National Natural Science Foundation of China (Grant No. 51261130091) for the DanishChinese Center for Nanometals, within which part of this work was performed. ZYB also 
acknowledges Professor N. Tsuji and Dr. Y. Sun for providing access to experimental facilities and for help with the ARB-processing. NK thanks for a financial support by the Grant-in-Aid for Scientific Research on Innovative Area "Bulk Nanostructured Metals" (No.22102006) through the Ministry of Education, Culture, Sports, Science and Technology of Japan.

\section{References}

[1] R.Z. Valiev, R.K. Islaimgaliev, I.V. Alexandrov, Prog. Mater. Sci. 45 (2000) 103-189.

[2] Y. Saito, N. Tsuji, H. Utsunomiya, T. Sakai, R.G. Hong, Scripta Mater. 39 (1998) 1221-1227.

[3] O.V. Mishin, D. Juul Jensen, N. Hansen, Metall. Mater. Trans A 41 (2010) 2936-2948.

[4] Y. Saito, H. Utsunomiya, N. Tsuji, T. Sakai, Acta Mater. 47 (1999) 579-583.

[5] S.H. Lee, Y. Saito, T. Sakai, H. Utsunomiya, Mater. Sci. Eng. A 325 (2002) 228-235.

[6] H-W. Kim, S-B. Kang, N. Tsuji, Y. Minamino, Acta Mater. 53 (2005) 1737-1749.

[7] H. Pirgazi, A. Akbarzadeh, R. Petrov, L. Kestens, Mater. Sci. Eng. A 497 (2008) 132-138.

[8] M.R. Rezaei, M.R. Toroghinejad, F. Ashrafizadeh, Mater. Sci. Eng. A 528 (2011) 442-446.

[9] H.W. Höppel, J. May, M. Göken, Adv. Eng. Mater. 6 (2004) 781-784.

[10] S. Roy, S.D. Singh, S. Suwas, S. Kumar, K. Chattopadhyay, Mater. Sci. Eng. A 528 (2006) 8469-8478.

[11] Y.H. Jang, S.S. Kim, S.Z. Han, C.Y. Lim, C.J. Kim, M. Goto, Scr. Mater. 52 (2005) 21-24.

[12] B.L. Li, N. Tsuji, N. Kamikawa, Mater. Sci. Eng. A 423 (2006) 331-342.

[13] S. Ohsaki, S. Kato, N. Tsuji, T. Ohkubo, K. Hono, Acta Mater. 55 (2007) 2885-2895.

[14] M. Shaarbaf, M.R. Toroghinejad, Mater. Sci. Eng. A 473 (2008) 28-33.

[15] D. Terada, S. Inoue, N. Tsuji, J. Mater. Sci. 42 (2007) 1673-1681. 
[16] P.P. Bhattacharjee, N. Tsuji, R.K. Ray, Metall. Mater. Trans. A 42 (2011) 2769-2780.

[17] P.P. Bhattacharjee, N. Tsuji, Mater. Sci. Forum 667-669 (2011) 1189-1194.

[18] P.P. Bhattacharjee, D. Terada, N. Tsuji, in: A. Haldar, S. Suwas, D. Bhattacharjee (eds.), Microstructure and texture in steels, Springer 2009. pp 421-429.

[19] O.V. Mishin, B. Bay, D. Juul Jensen, Metall. Mater. Trans. A 31 (2000) 1653-1662.

[20] D.A. Hughes, N. Hansen, Acta Mater. 48 (2000) 2985-3004.

[21] D.A. Hughes, N. Hansen, Metal. Trans. A 24 (1993) 2021-2037.

[22] F.J. Humphreys, J. Mater. Sci. 36 (2001) 3833-3854.

[23] O.V. Mishin, A. Godfrey, L. Östensson, Metall. Mater. Trans. A 37 (2006) 489-496.

[24] W.Q. Cao, A. Godfrey, Q. Liu, Mater. Sci. Eng. A 361 (2003) 9-14.

[25] S.E. Schoenfeld, R.J. Asaro, Int. J. Mech. Sci. Vol. 38 (1996), 661-683.

[26] N. Kamikawa, T. Sakai, N. Tsuji, Acta Mater. 55 (2007) 5873-5888.

[27] X. Huang, N. Tsuji, N. Hansen, Y. Minamino, Mater. Sci. Eng. A 340 (2003) 265-271.

[28] H.W. Zhang, X. Huang, N. Hansen, Acta Mater. 56 (2008) 5451-5465.

[29] A.P. Zhilyaev, B.-K. Kim, J.A. Szpunar, M.D. Baró, T.G. Langdon, Mater. Sci. Eng. A 391 (2005) 377-389.

[30] K.S. Raju, M.G. Krishna, K.A. Padmanabhan, K. Muraleedharan, N.P. Gurao, G. Wilde, Mater. Sci. Eng. A 491 (2008) 1-7.

[31] N. Takata, S.-H. Lee, N. Tsuji, Mater. Let. 63 (2009) 1757-1760.

[32] T. Knudsen, W.Q. Cao, A. Godfrey, Q. Liu, N. Hansen, Metal. Mater. Trans. A 39 (2008) $430-440$.

[33] H.W. Zhang, K. Lu, R. Pippan, X. Huang, N. Hansen, Scr. Mater. 65 (2011) 481-484.

[34] N. Hansen, Scripta Mater. 51 (2004) 801-806. 
[35] A.W. Thompson, Acta Metall. 23 (1975) 1337-1342.

[36] Q. Liu, X. Huang, D.J. Lloyd, N. Hansen, Acta Mater. 50 (2002) 3789-3802.

[37] N. Kamikawa, X. Huang, N. Tsuji, N. Hansen, Acta Mater. 57 (2009) 4198-4208.

[38] X. Zhang, N. Hansen, Y. Gao, X. Huang, Acta Mater. 60 (2012) 5933-5943.

[39] H.W. Zhang, X. Huang, R. Pippan, N. Hansen, Acta Mater. 58 (2010) 1698-1707. 


\section{Figure captions}

Figure 1. Microstructure and texture of the initial material used for ARB: (a) EBSD map from the longitudinal section and (b) $\{111\}$ pole figure. In (a) low angle $\left(1.5-15^{\circ}\right)$ misorientations are represented by gray lines; twin boundaries are shown in red; other high angle boundaries are depicted by black lines. The scale bar is parallel to the normal direction. The large variety of orientations in (b) indicates a very weak texture.

Figure 2. EBSD maps showing the microstructure in the longitudinal section of samples after different numbers of ARB cycles: (a) 3 cycles; (b) 6 cycles and (c) 8 cycles. Low angle $\left(1.5-15^{\circ}\right)$ misorientations and HABs are shown by gray and bold black lines, respectively. The scale bar is parallel to the RD.

Figure 3. An EBSD map showing an interface region with incomplete bonding (marked by arrows) near a coarse oxide particle (seen as large dark strain) in the sample after 6 ARB cycles. Low angle $\left(1.5-15^{\circ}\right)$ misorientations and HABs are shown by gray and bold black lines, respectively. The scale bar is parallel to the $\mathrm{RD}$.

Figure 4. Evolution of quantitative microstructural parameters in Ni during ARB: (a) fraction of HABs calculated from the EBSD data; (b) spacing along the ND between HABs, $d_{\mathrm{HAB}}$, measured in the EBSD maps and between all boundaries, $d_{\mathrm{all}}$, seen in TEM micrographs. 
Figure 5. TEM image from the longitudinal section of nickel after 3 ARB cycles. The scale bar is nearly parallel to the RD.

Figure 6. Engineering stress-strain curves for nickel before and after ARB.

Figure 7. Evolution of $0.2 \%$ proof stress and uniform elongation with increasing number of ARB cycles.

Figure 8. Misorientation distributions obtained from EBSD data on ARB-processed and CR nickel deformed to a von Mises strain of 2.4.

Figure 9. Hall-Petch plot combining the data for the ARB samples investigated in the present work and for Ni samples deformed by either conventional rolling or HPT [20,32,33]. Open and solid symbols represent values obtained from tensile tests $(0.2 \%$ proof stress $)$ and from Vickers hardness measurements, respectively. 


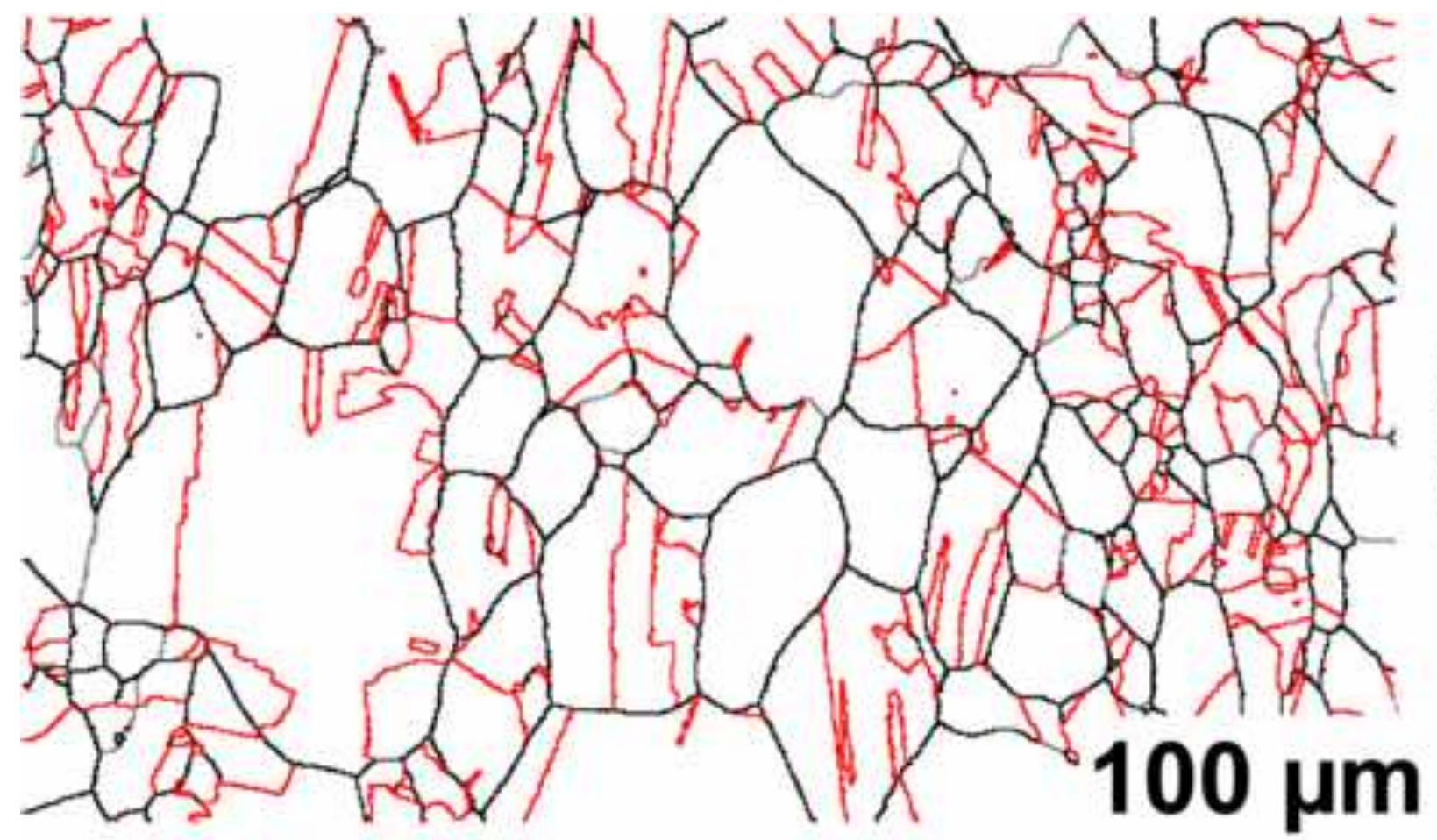

(a)

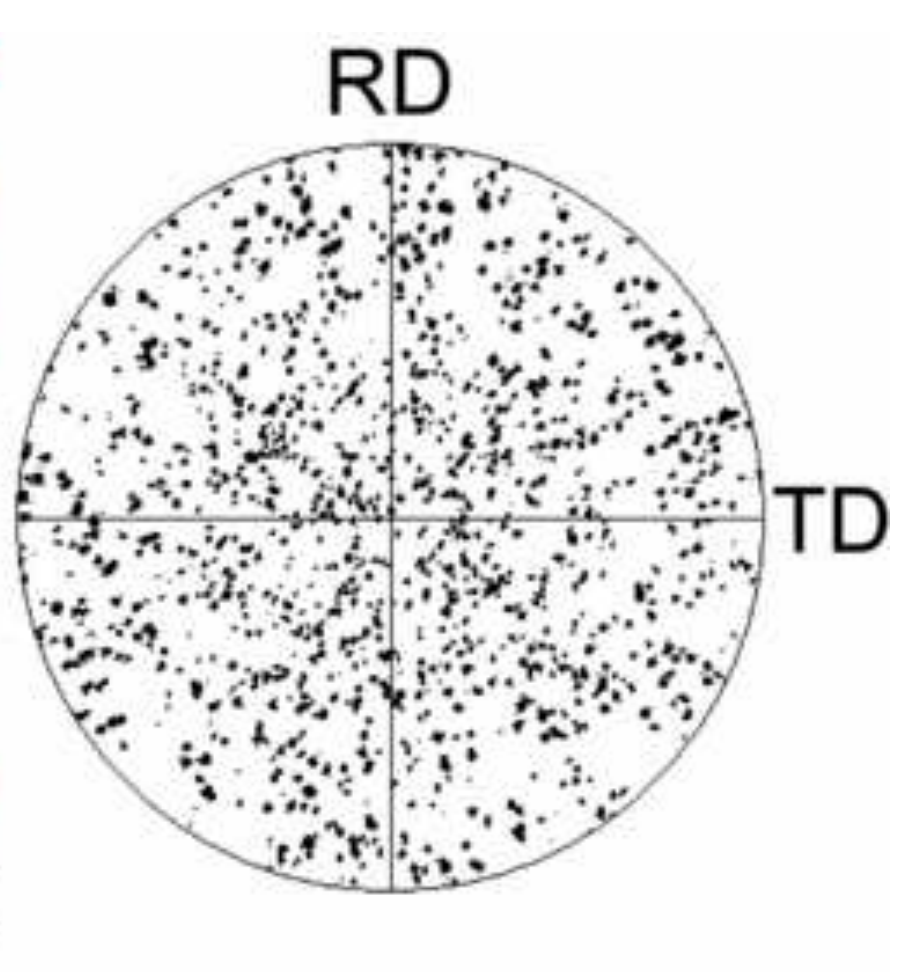

(b)

Fig. 1. Microstructure and texture of the initial material used for ARB: (a) EBSD map from the longitudinal section and (b) $\{111\}$ pole figure. In (a) low angle $\left(1.5-15^{\circ}\right)$ misorientations are represented by gray lines; twin boundaries are shown in red; other high angle boundaries are depicted by black lines. The scale bar is parallel to the normal direction. The large variety of orientations in (b) indicates a very weak texture. 
Figure 2 (this figure should span over 2 columns)

Click here to download high resolution image

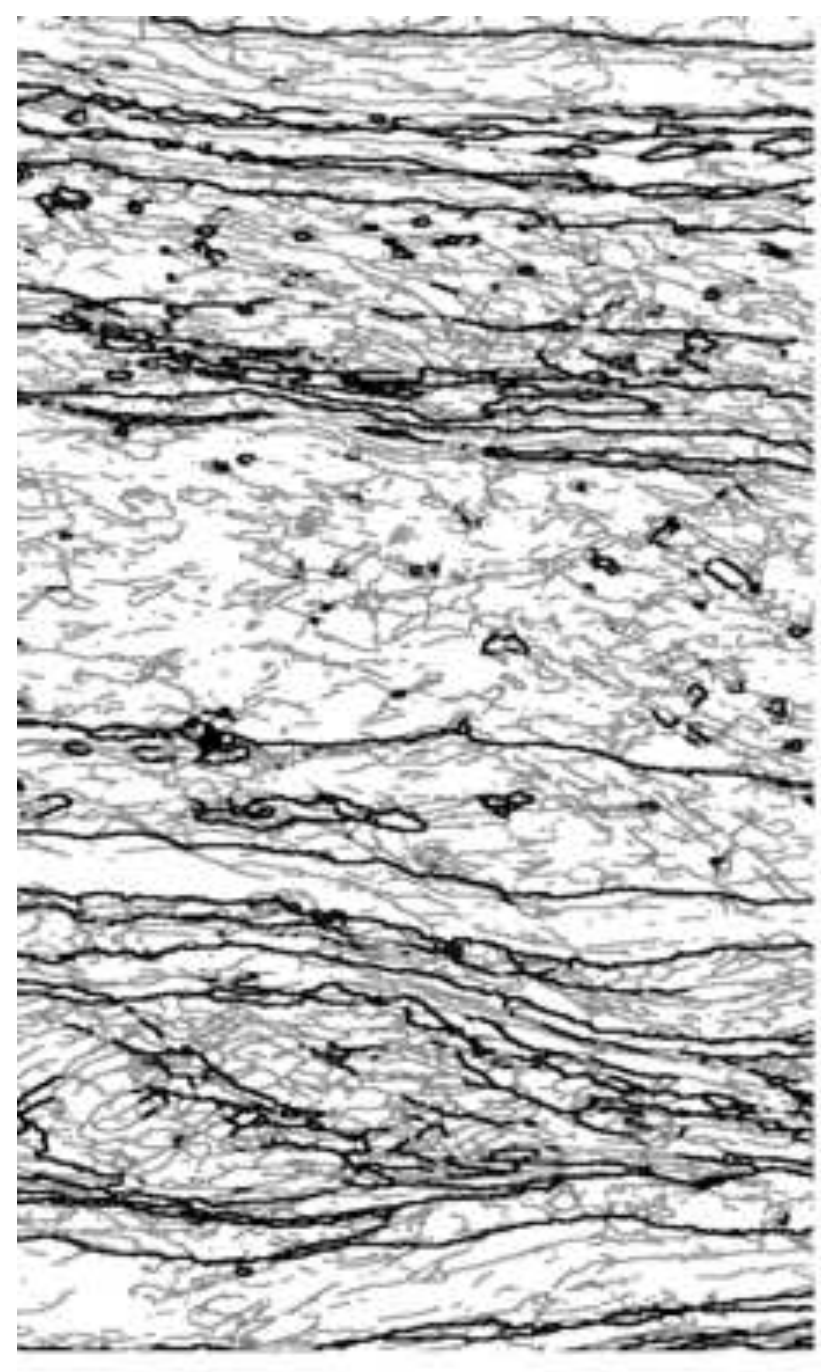

(a)

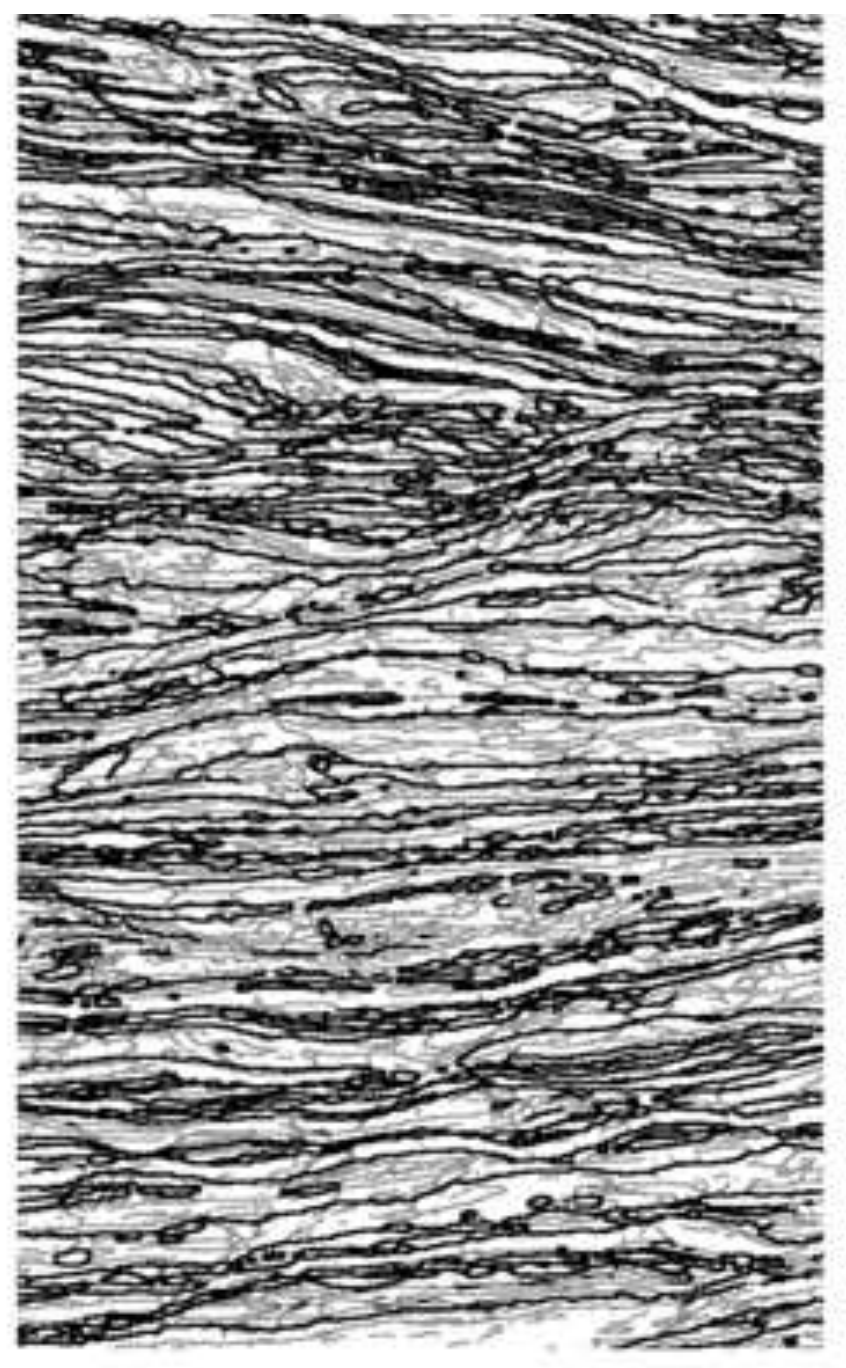

(b)

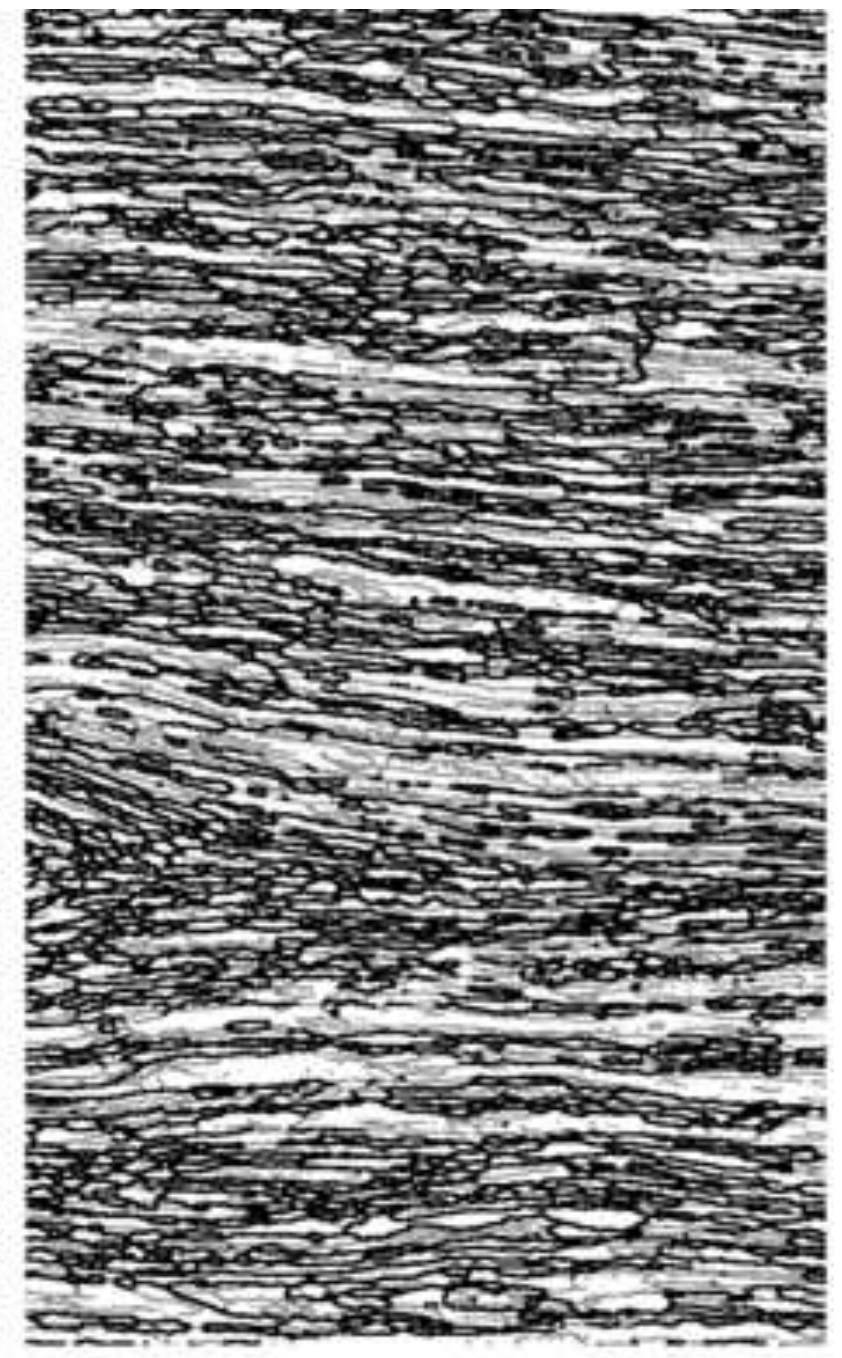

(c)

$5 \mu \mathrm{m}$

Figure 2. EBSD maps showing the microstructure in the longitudinal section of samples after different numbers of ARB cycles: (a) 3 cycles; (b) 6 cycles and (c) 8 cycles. Low angle $\left(1.5-15^{\circ}\right)$ misorientations and HABs are shown by gray and bold black lines, respectively. The scale bar is parallel to the RD. 


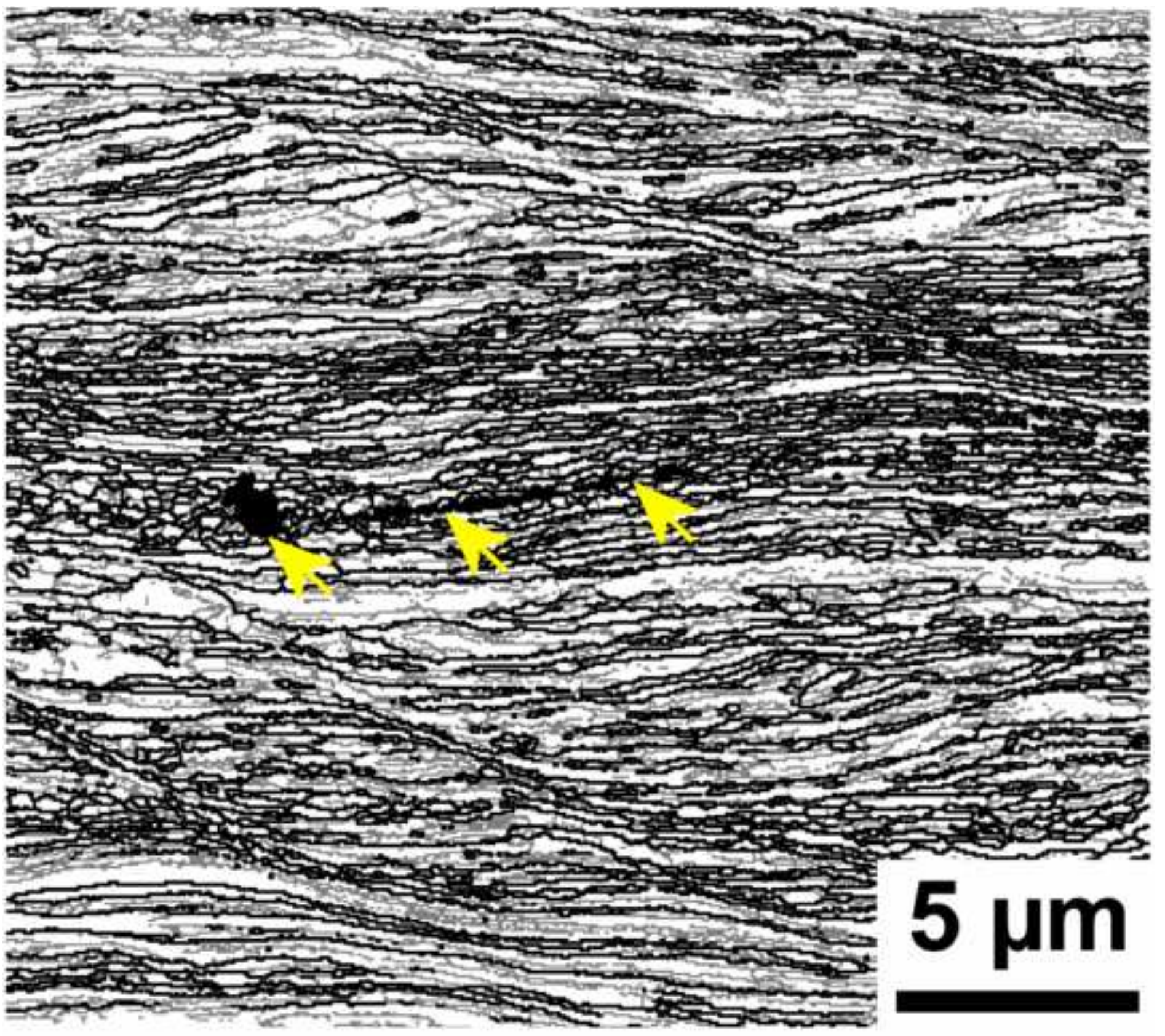

Figure 3. An EBSD map showing an interface region with incomplete bonding (marked by arrows) near a coarse oxide particle (seen as large dark strain) in the sample after $6 \mathrm{ARB}$ cycles. Low angle $\left(1.5-15^{\circ}\right)$ misorientations and HABs are shown by gray and bold black lines, respectively. The scale bar is parallel to the RD. 


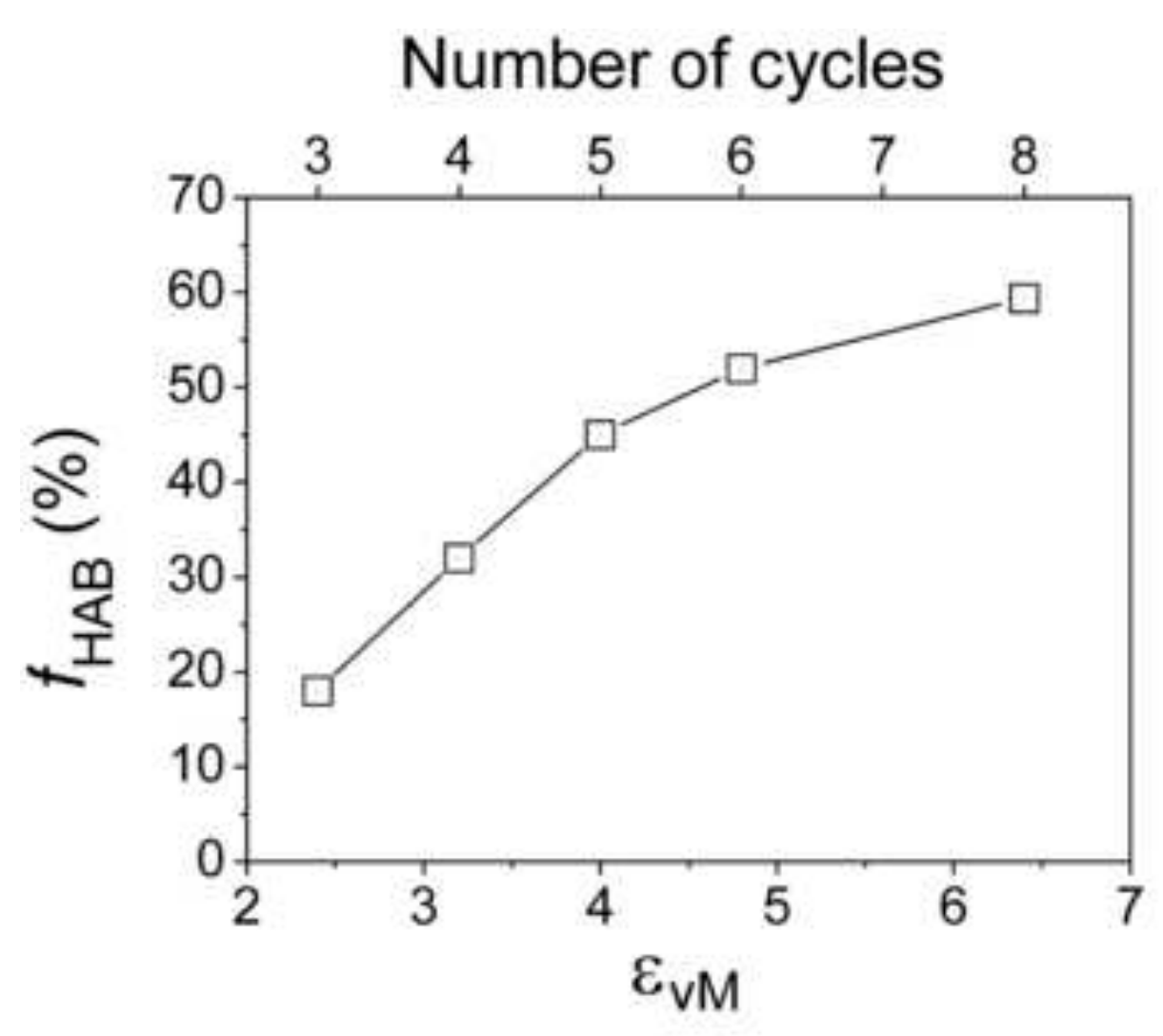

(a)

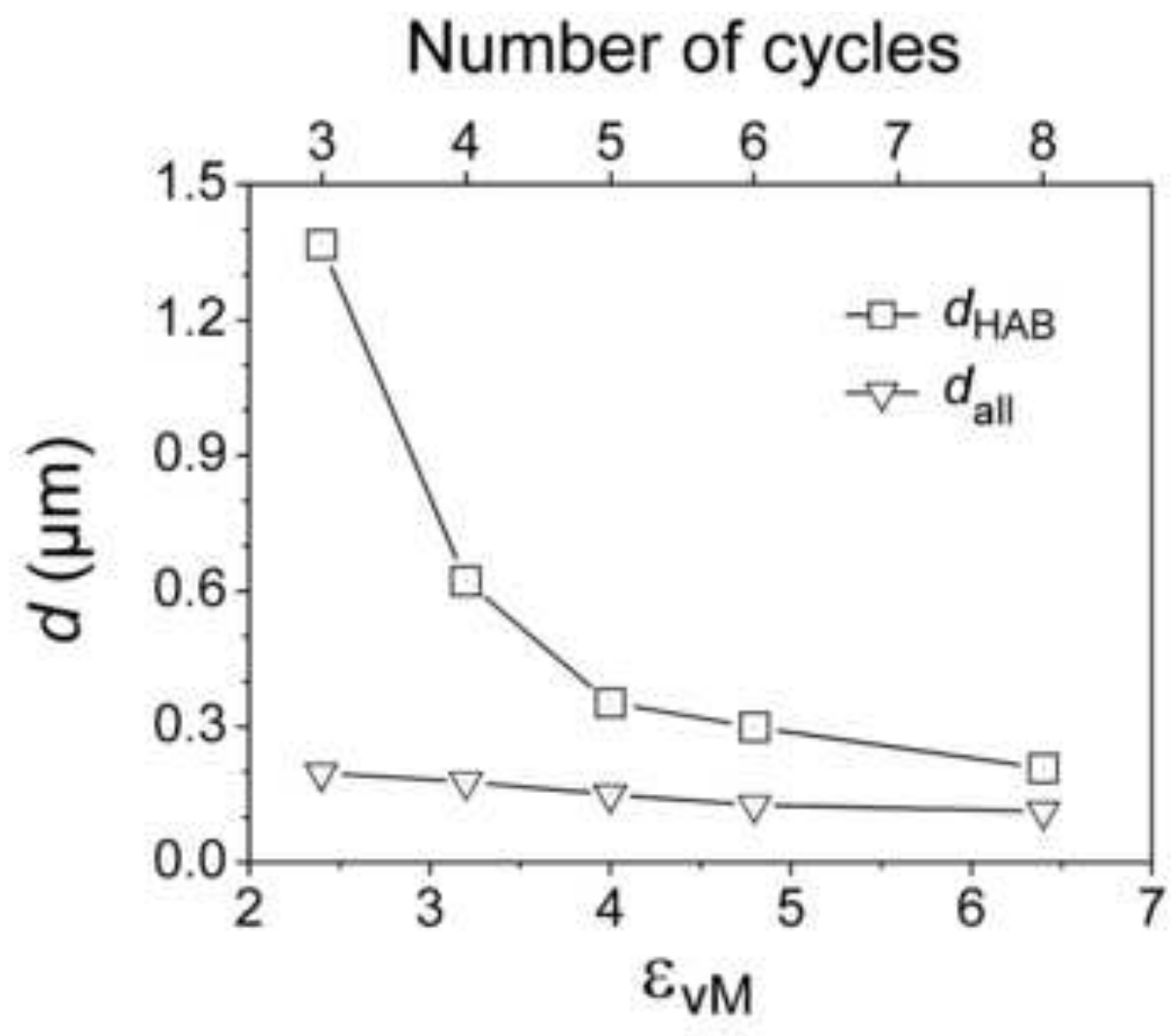

(b)

Figure 4. Evolution of quantitative microstructural parameters during ARB: (a) fraction of HABs calculated from the EBSD data; (b) spacing along the ND between HABs, $d_{\mathrm{HAB}}$, measured in the EBSD maps and between all boundaries, $d_{\mathrm{all}}$, seen in TEM micrographs. 
Click here to download high resolution image

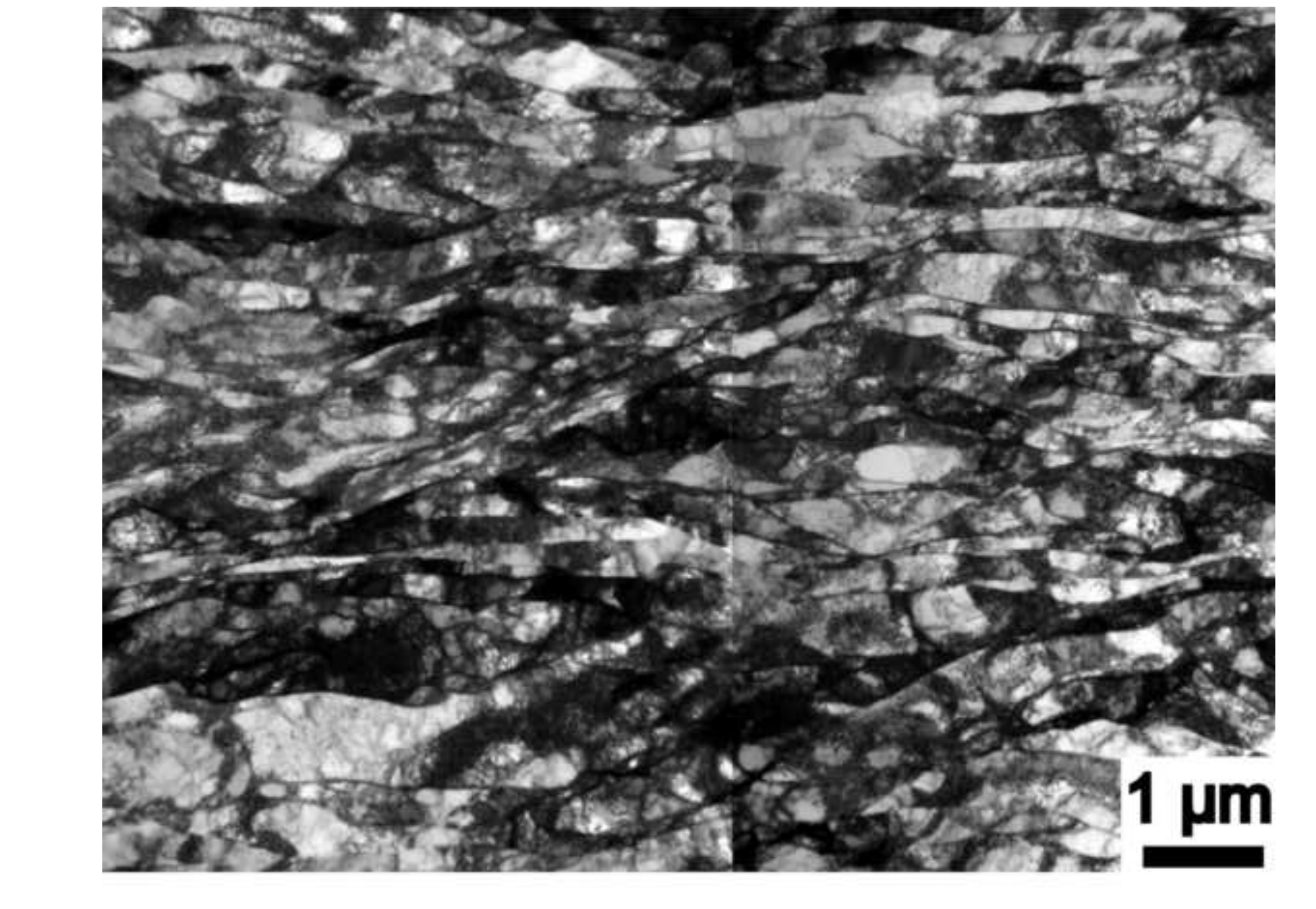

Figure 5. TEM image from the longitudinal section of nickel
after 3 ARB cycles. The scale bar is nearly parallel to the RD.

Figure 5 . TEM image from the longitudinal section of nickel
after 3 ARB cycles. The scale bar is nearly parallel to the RD.

$$
\text { ar cycles. The scale bar is nearly parallel to the RD. }
$$
and

$$
\text { - }
$$$$
\text { 列 }
$$$$
\text { - }
$$

.

(n)

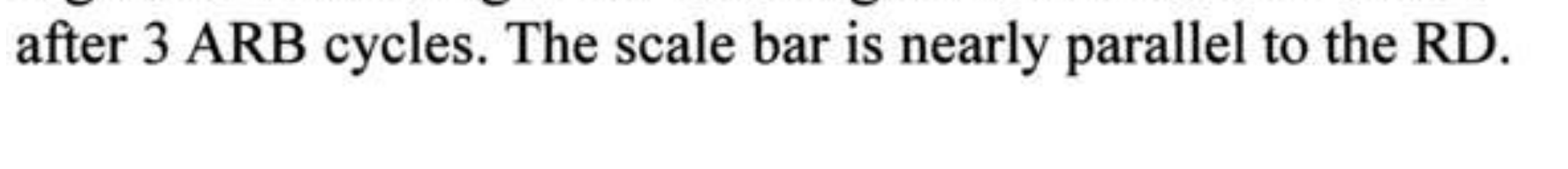




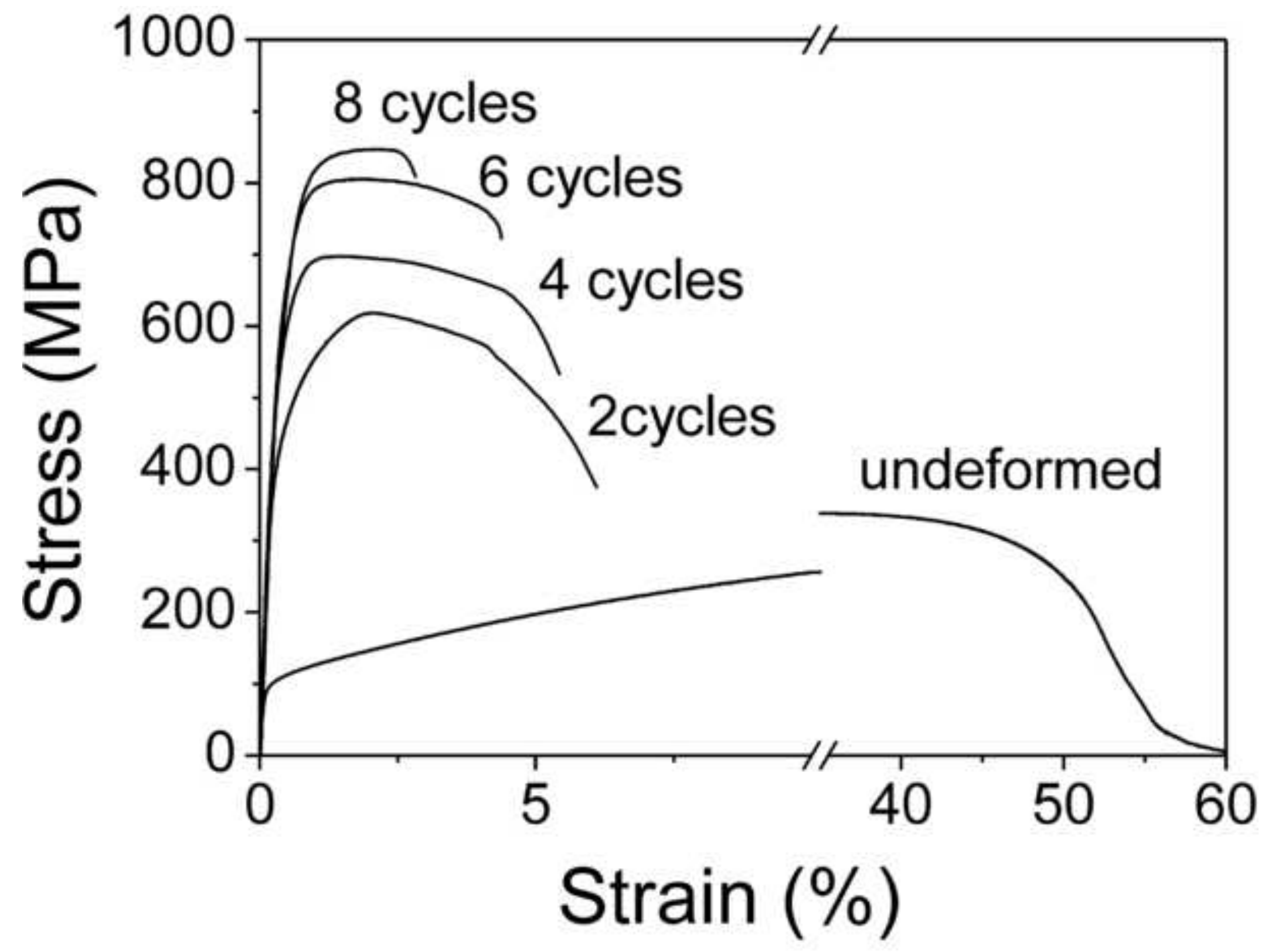

Figure 6. Engineering stress-strain curves for nickel before and after ARB 
Number of cycles

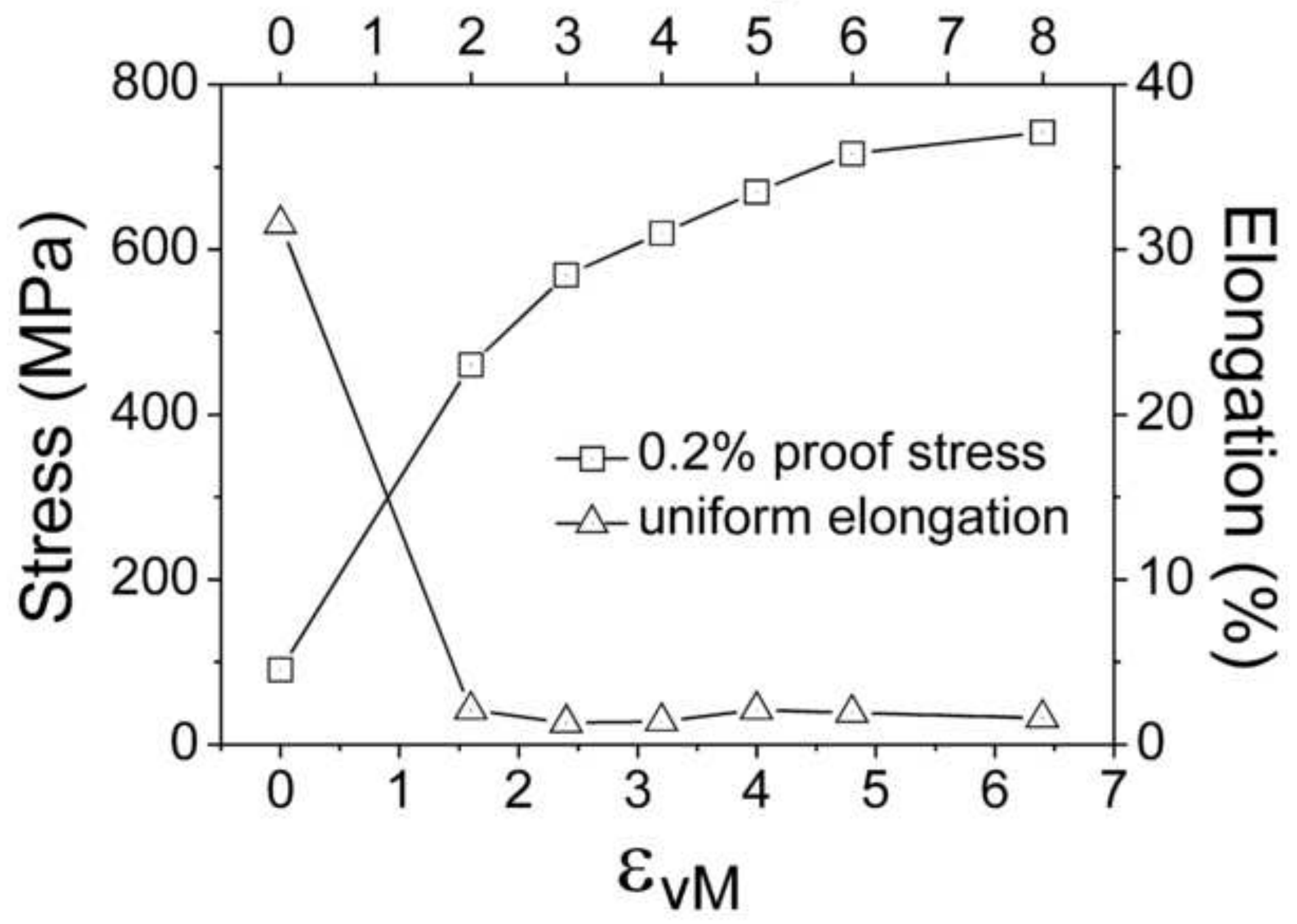

Figure 7. Evolution of $0.2 \%$ proof stress and uniform elongation with increasing number of $\mathrm{ARB}$ cycles. 


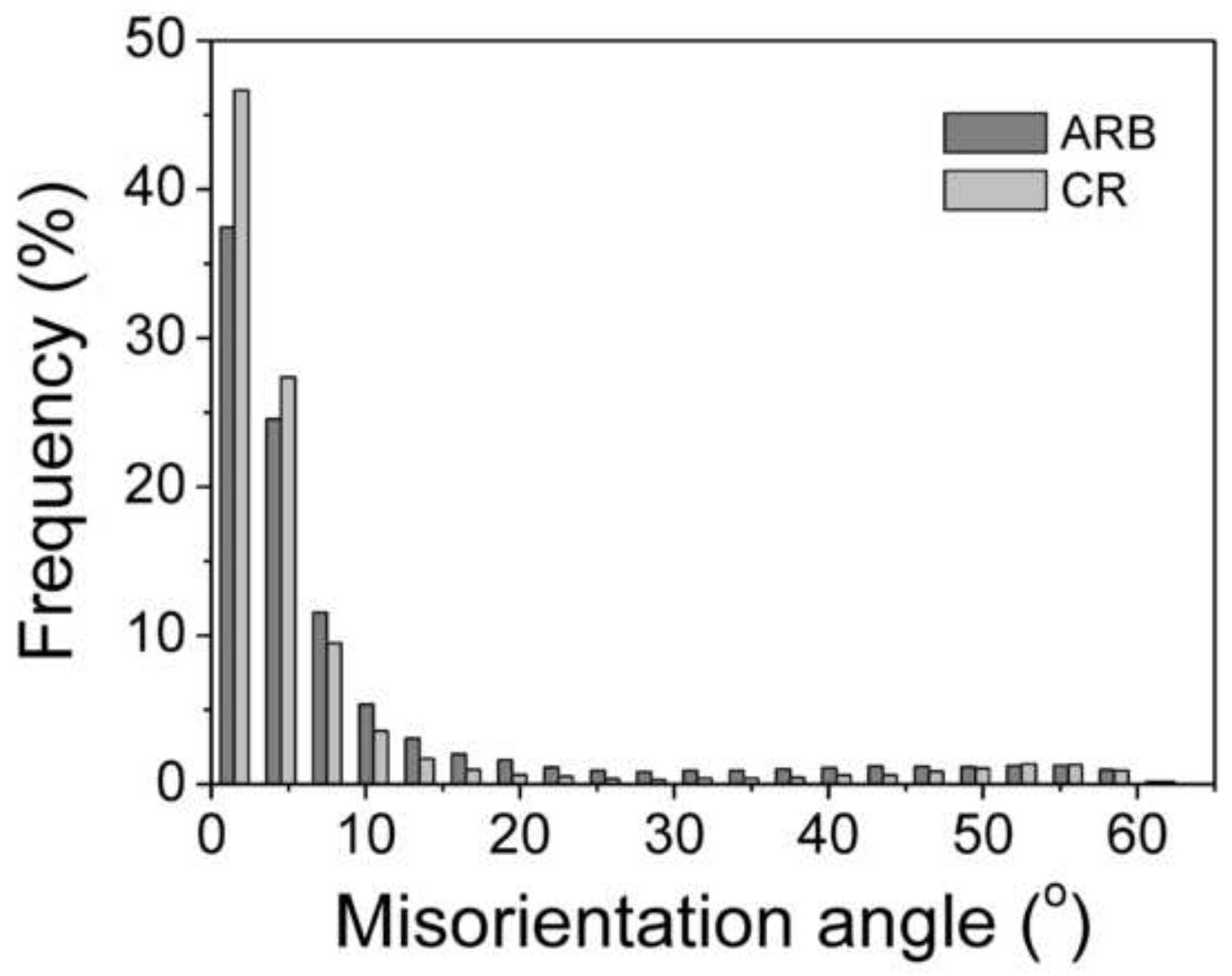

Figure 8. Misorientation distributions obtained from EBSD data on ARB-processed and CR nickel deformed to a von Mises strain of 2.4 


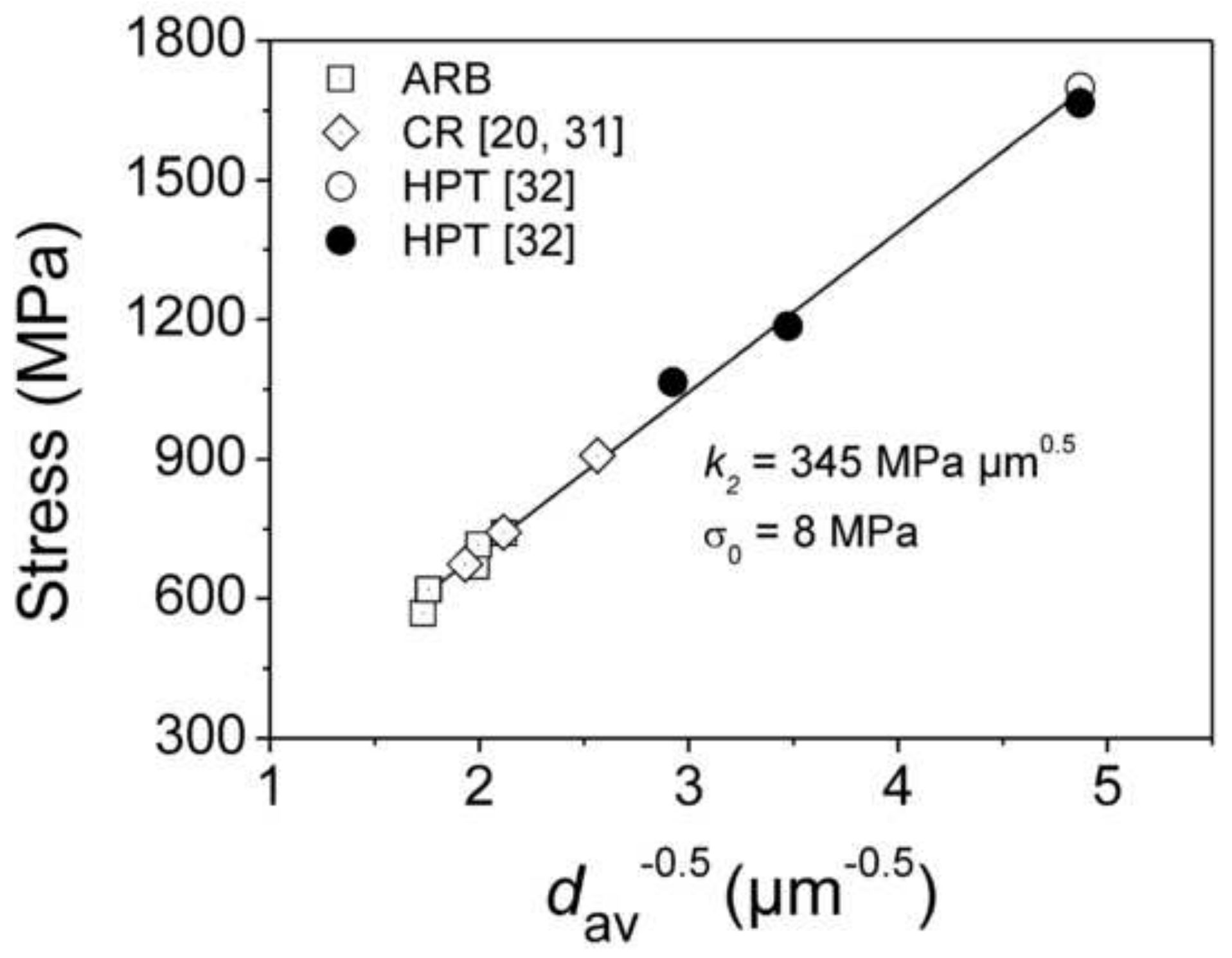

Figure 9. Hall-Petch plot combining the data for the ARB samples investigated in the present work and for $\mathrm{Ni}$ samples deformed by either conventional rolling or HPT $[20,32,33]$. Open and solid symbols represent values obtained from tensile tests $(0.2 \%$ proof stress) and from Vickers hardness measurements, respectively. 
Table 1: Main impurities in $\mathrm{Ni}$ (wt. \%) used in the present experiment.

\begin{tabular}{ccccccc}
\hline Fe & $\mathrm{Si}$ & $\mathrm{P}$ & $\mathrm{Al}$ & $\mathrm{Mg}$ & $\mathrm{Mn}$ & $\mathrm{Ti}$ \\
\hline 0.009 & 0.005 & 0.004 & 0.003 & 0.003 & 0.002 & 0.002 \\
\hline
\end{tabular}


Table 2: Microstructural parameters and hardness of the ARB and CR samples after a von Mises strain of 2.4 .

\begin{tabular}{lccccc}
\hline Sample & $d_{\mathrm{LAB}}$ & $d_{\mathrm{HAB}}$ & $f_{\mathrm{HAB}}$ & $\mathrm{L}_{\mathrm{A}[\mathrm{HAB}]}$ & $\mathrm{HV}_{200 \mathrm{~g}}$ \\
& $(\mu \mathrm{m})$ & $(\mu \mathrm{m})$ & $(\%)$ & $\left(\mu \mathrm{m}^{-1}\right)$ & \\
\hline ARB & 0.22 & 1.4 & 18 & 1.01 & $232 \pm 6$ \\
$\mathrm{CR}$ & 0.26 & 1.9 & 11 & 0.52 & $219 \pm 4$ \\
\hline
\end{tabular}


Table 3. Values of $k_{2}$ for different $\theta_{\mathrm{c}}, f$ and $\theta_{\mathrm{av}}$ determined for CR and ARB samples using either TEM or EBSD techniques.

\begin{tabular}{|c|c|c|c|c|c|c|}
\hline \multicolumn{3}{|c|}{ Characterization } & \multirow[b]{2}{*}{$\theta_{\mathrm{c}}\left(^{\circ}\right)$} & \multirow[b]{2}{*}{$f$} & \multirow[b]{2}{*}{$\theta_{\mathrm{av}}\left({ }^{\circ}\right)$} & \multirow{2}{*}{$\begin{array}{c}k_{2} \\
\left(\mathrm{MPa}_{\mu} \mathrm{m}^{0.5}\right)\end{array}$} \\
\hline Sample & technique & $\varepsilon_{\mathrm{vM}}$ & & & & \\
\hline \multirow{8}{*}{$\mathrm{CR}$} & \multirow{6}{*}{ TEM [20] } & 1.4 & & 0.17 & 2.3 & 348 \\
\hline & & 2.7 & 6 & 0.27 & 2.6 & 363 \\
\hline & & 4.5 & & 0.41 & 2.5 & 352 \\
\hline & & 1.4 & & 0.29 & 1.8 & 318 \\
\hline & & 2.7 & 4 & 0.41 & 2.0 & 324 \\
\hline & & 4.5 & & 0.51 & 2.0 & 316 \\
\hline & \multirow{2}{*}{ EBSD } & 2.7 & & 0.43 & 2.7 & 361 \\
\hline & & 4.5 & 0 & 0.70 & 2.7 & 319 \\
\hline \multirow{5}{*}{$\mathrm{ARB}$} & \multirow{5}{*}{ EBSD } & 2.4 & & 0.38 & 2.7 & 364 \\
\hline & & 3.2 & & 0.53 & 2.8 & 353 \\
\hline & & 4.0 & 6 & 0.67 & 2.8 & 328 \\
\hline & & 4.8 & & 0.72 & 2.9 & 321 \\
\hline & & 6.4 & & 0.79 & 3.0 & 304 \\
\hline
\end{tabular}

